\title{
Sifat Biologi Tanah Pada Lahan Aplikasi dan Tanpa Aplikasi Tandan Kosong Kelapa Sawit di Adolina PT. Perkebunan Nusantara IV
}

\section{Soil Biological Characteristics on Land With and Without The Application of Oil Palm Empty Fruit Bunch At Adolina PT. Perkebunan Nusantara IV}

\author{
Sakiah $^{1 *}$, Ade Firmansyah ${ }^{2}$, dan Dina Arfianti ${ }^{3}$ \\ ${ }^{1,2,3}$ Program Studi Budidaya Perkebunan, STIPER Agrobisnis Perkebunan (STIP-AP), Medan \\ *E-mail : sakiah@stipap.ac.id
}

\begin{abstract}
Oil palm empty fruit bunches (OPEFB) is one of the solid wastes from the processing of palm oil into crude palm oil. Generally, OPEFB is used as mulch on oil palm plantations. This study aims to compare the soil biological properties on land with the application of $O P E F B$ and land without the application of OPEFB in a depth of $0-20 \mathrm{~cm}$ and $20-40 \mathrm{~cm}$. Soil sampling was carried out at Adolina, PT Perkebunan Nusantara IV, in block 06 A (land with the application of OPEFB) and block $06 B$ (land without the application of OPEFB). The observation parameters are organic matter content, total microbes, and soil respiration. Then, the data analysis results are processed with SPSS version 20. The test was using a ttest. The research results of oil palm empty fruit bunches application with a dose of 35 tons ha-1 which were applied evenly without layering on the oil palm plantations aged 13 years can increased soil organic matter content at a depth of 0-20 cm but does not increase total microbes and soil respiration both at a depth of $0-20 \mathrm{~cm}$ and at a depth of $20-40 \mathrm{~cm}$ compared with total microbes and soil respiration on land without the application of OPEFB.
\end{abstract}

Keywords: organic matter, soil respiration, total microbes

Disubmit : 6 Januari 2020; Diterima: 5 Februari 2020; Disetujui : 11 Maret 2020

\section{PENDAHULUAN}

Kelapa sawit telah menyebar pada sebagian besar wilayah Indonesia dan menjadi penggerak pertumbuhan dan ekonomi wilayah. Luas areal perkebunan kelapa sawit di Indonesia pada tahun 2015 mencapai 11.260.277 ha dan produksi minyak kelapa sawit mencapai 31.070.015 ton dan mengalamai peningkatan pada tahun 2016 menjadi 11.914 .499 ha dan produksi minyak kelapa sawit mencapai 33.229.381 ton (Dirjenbun, 2016). Peningkatan luas areal kelapa sawit yang diiringi dengan peningkatan produksi kelapa sawit memiliki konsekuensi berupa peningkatan jumlah limbah kelapa sawit yang dihasilkan. Tandan Kosong Kelapa Sawit (TKKS) merupakan salah satu limbah dari pabrik yang jumlahnya sangat melimpah (Gurmit, Manoharan and San, 1989). Pengolahan kelapa sawit menjadi minyak sawit mentah akan menghasilkan TKKS 20 - $23 \%$ dari total tandan buah segar yang diolah dan ini masih menjadi permasalahan dalam agroindustri perkebunan (Silalahi and Supijatno, 2017); (Darmosarkoro and Rahutomo, 2010). 
Strategi yang perlu ditempuh dalam pengelolaan limbah TKKS adalah antara lain mengurangi volume limbah, menurunkan daya cemar limbah dan meningkatkan nilai tambah (Said, 1996). Penelitian pengolahan dan pemanfaatan untuk peningkatan nilai tambah TKKS akhir-akhir ini telah banyak dilakukan. TKKS sebagai pulp untuk karton pada skala usaha kecil (Anggraini and Roliadi, 2011), TKKS sebagai material tekstil (Putri and Wardani, 2014), TKKS sebagai biobriket arang sumber energi alternatif (Giyanto and Sinaga, 2019), serta sebagai bahan baku kompos (Sembiring, Sipayung and Sitepu, 2014). Hasil penelitian tersebut mengemukakan masih perlu penyempurnaan produk agar dapat dimanfaatkan secara optimal.

Penanganan limbah TKKS dengan cara mengembalikan ke lahan perkebunan masih menjadi pilihan bagi pelaku perkebunan kelapa sawit karena TKKS merupakan bahan organik yang memiliki potensi sebagai bahan pembenah tanah dan sumber hara bagi tanaman, potensi ini didasarkan pada materi TKKS yang merupakan bahan organik dan sebagai sumber hara. TKKS mengandung $42,8 \% \mathrm{C}, 2,90 \% \mathrm{~K}_{2} \mathrm{O}, 0,80 \% \mathrm{~N}$, $0,22 \% \mathrm{P}_{2} \mathrm{O}_{5}, 0,30 \% \mathrm{MgO}$ dan unsur-unsur mikro antara lain $10 \mathrm{ppm} \mathrm{B}, 23 \mathrm{pmm} \mathrm{Cu}$, dan $51 \mathrm{ppm} \mathrm{Zn}$ (Darmosarkoro and Rahutomo, 2010). Aplikasi TKKS pada tanaman belum menghasilkan (TBM) dilakukan dengan cara meletakkan atau menyusun TKKS sekeliling piringan pada jarak $\pm 30 \mathrm{~cm}$ dari pangkal batang pada TBM 0 dan jarak $\pm 50 \mathrm{~cm}$ dari pangkal batang pada TBM 1-3, sedangkan pada tanaman menghasilkan diaplikasikan di gawangan mati, penebaran secara merata hingga ke pinggir piringan (Wahyuni and Sakiah, 2019).

Tanah merupakan media tempat tumbuhnya tanaman. Tanah juga merupakan habitat bagi berbagai organisme yang hidup di dalamnya. Organisme tanah berperan dalam proses dekomposisi bahan organik, distribusi dan pencampuran bahan organik serta menjadi musuh bagi patogen yang menyerang tanaman. Oleh karena itu keberadaan organisme tanah sangat penting dalam membantu pertumbuhan dan produktivitas tanaman (Widyati, 2013). Berbagai hasil penelitian mengindikasikan bahwa sebagian besar lahan pertanian intensif menurun produktivitasnya dan telah mengalami degradasi lahan, terutama terkait dengan sangat rendahnya bahan organik dalam tanah yaitu $<2 \%$ (Suriadikarta, D and Simanungkalit, 2012).

Bahan organik akan mengalami proses dekomposisi secara bertahap, akibat penggunaan kandungan unsur hara karbon oleh mikroorganisme dalam mendapatkan energi untuk kehidupannya melalui proses respirasi. Total mikroba dalam tanah dapat digunakan sebagai indeks kesuburan tanah tanpa mempertimbangkan hal-hal lain, karena pada tanah subur jumlah mikrobanya tinggi. Populasi yang tinggi menggambarkan adanya suplai makanan atau energi yang cukup ditambah temperatur yang sesuai, ketersediaan air cukup, dan kondisi ekologi lain yang mendukung (Anas, 1989).

Berdasarkan paparan diatas, maka dilakukan penelitian yang bertujuan untuk membandingkan sifat biologi tanah, dalam hal ini kadar bahan organik, total mikroba dan respirasi tanah pada lahan aplikasi dan tanpa aplikasi TKKS kedalaman 0-20 cm dan 20-40 cm.

\section{METODE PENELITIAN}

Penelitian dilaksanakan pada bulan Maret hingga Juli 2019, sampel tanah diambil di Afdeling I Kebun Adolina PT. Perkebunan Nusantara IV pada blok 06A sebagai lahan aplikasi TKKS dan blok 06B sebagai lahan tanpa aplikasi TKKS. Aplikasi TKKS blok 06A dilakukan pada bulan September 2018, dosis 35 ton ha-1. TKKS ditebar merata tanpa berlapis antar pokok baris tanaman kelapa sawit. Pada lahan aplikasi dan tanpa aplikasi TKKS terdapat kelapa sawit tahun tanam 2006 (umur 13 tahun). Penetapan titik pengambilan sampel tanah agregat menggunakan metode random sampling,titik pengambilan sampel tepatnya berada pada areal antar pokok baris tanaman kelapa sawit. Areal pengambilan sampel terlebih dahulu dibersihkan dari gulma, pengambilan sampel tanah agregat dilakukan dengan cara menggali tanah pada kedalaman $0-20 \mathrm{~cm}$ dan 20-40 cm dengan menggunakan cangkul. Sampel tanah dari areal aplikasi diambil dari 9 titik yang berbeda kemudian digabung menjadi satu, demikian juga pada lahan tanpa aplikasi TKKS. Jumlah sampel tanah ada 2 (lahan aplikasi, lahan tanpa aplikasi) x 2 (kedalaman 0-20 cm dan 20-40 cm) x 3 ulangan. Satu 
petak sampel berukuran $9 \mathrm{~m}$ x $7 \mathrm{~m}$. Selanjutnya sampel tanah dianalisa di Laboratorium Biologi Tanah, Fakultas Pertanian, Universitas Sumatera Utara. Data diolah secara statistik dengan software SPSS versi 20, uji dilakukan dengan menggunakan t-test. Hipotesis penelitian yaitu $\mathrm{HO}=$ tidak ada perbedaan bahan organik, total mikroba dan respirasi tanah antara lahan aplikasi TKKS dan tanpa aplikasi TKKS. H1 = ada perbedaan bahan organik, total mikroba dan respirasi tanah antara lahan aplikasi TKKS dan tanpa aplikasi TKKS. Kriteria pengujian adalah $\mathrm{H} 0: \mu 1=\mu 2$ dan $\mathrm{H} 1: \mu 1 \neq \mu 2$, sehingga $\mathrm{H} 0$ akan diterima bila t-hitung < t-tabel (sig : 0,05) dan H1 akan diterima bila t-hitung > t-tabel (sig : 0,05)

Bahan yang digunakan pada penelitian ini yaitu tanah agregat dan tanah komposit, natrium agar, $\mathrm{KOH}$, aquadest, phenolftalein, $\mathrm{K} 2 \mathrm{Cr} 2 \mathrm{O} 7, \mathrm{H} 2 \mathrm{SO} 4, \mathrm{H} 3 \mathrm{PO} 4$, difenilamin, $\mathrm{NaF}, \mathrm{Fe}(\mathrm{NH} 4) 2 \mathrm{SO} 4$. Alat yang digunakan yaitu cangkul, bor tanah, mortal, ayakan, plastik klip, timbangan, cawan petri, erlenmeyer, gelas ukur, botol semprot, buret dan alat pendukung lainnya di laboratorium.

Pengamatan yang dilakukan pada penelitian ini yaitu kadar bahan organik tanah dianalisa dengan metode Walkley and Black, total mikroba dengan metode Plate Count dan respirasi tanah dengan metode Jar (penangkapan $\mathrm{CO} 2$ ).

\section{HASIL DAN PEMBAHASAN}

Bahan Organik Tanah. Kandungan karbon dalam tanah mencerminkan kandungan bahan organik dalam tanah yang merupakan tolok ukur yang penting untuk pengelolaan tanah. Bahan organik merupakan salah satu bahan pembenah tanah yang mampu memperbaiki karakteristik fisik, kimia, dan biologi tanah (Dariah, 2007). TKKS sebagai salah satu limbah yang berasal dari pengolahan tandan buah segar menjadi minyak sawit mentah dijadikan sebagai sumber bahan organik di perkebunan kelapa sawit dengan cara mengaplikasikan TKKS di areal sekitar tanaman kelapa sawit. Perbandingan bahan organik tanah pada lahan aplikasi TKKS dan tanpa aplikasi TKKS di Afdeling I kebun Adolina dapat dilihat pada Tabel 1.

Tabel 1. Hasil analisis independent sample test kadar bahan organik pada lahan aplikasi dan tanpa aplikasi TKKS kedalaman 0-20 cm dan 20-40 cm

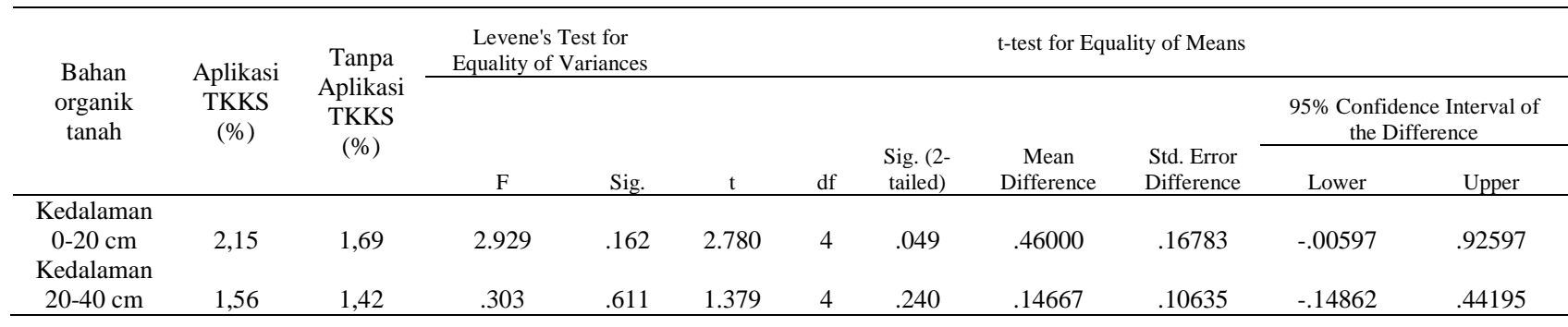

Nilai t-hitung kadar bahan organik tanah kedalaman $0-20 \mathrm{~cm}(2.780)>\mathrm{t}$ - tabel $(0,05)(4)(2.776)$ artinya bahwa hipotesis H1 diterima yaitu ada perbedaan bahan organik tanah pada lahan aplikasi TKKS dan tanpa aplikasi TKKS. Rata-rata bahan organik tanah pada lahan aplikasi TKKS kedalaman 0-20 cm yaitu 2,15\%, lebih tinggi dibanding pada lahan tanpa aplikasi TKKS (1,69\%). Namun, pada kedalaman 20-40 cm dapat dilihat bahwa nilai t-hitung (1.379) < t- tabel(0,05)(4)(2.776) artinya bahwa hipotesis H0 diterima yaitu tidak ada perbedaan bahan organik tanah pada lahan aplikasi TKKS dan tanpa aplikasi TKKS pada kedalaman 20$40 \mathrm{~cm}$. Rata-rata bahan organik tanah pada kedalaman 20-40 cm lahan aplikasi TKKS yaitu 1,56\% dan pada lahan tanpa aplikasi TKKS 1,42\%.

Pemanfaatan TKKS sebagai mulsa dengan dosis 35 ton ha-1 yang ditebar merata diantara baris tanaman kelapa sawit umur 13 tahun dapat meningkatkan kadar bahan organik tanah pada lapisan atas (0-20 $\mathrm{cm})$. TKKS dapat meningkatkan bahan organik tanah, selain mengembalikan bahan organik, TKKS juga berpotensi menambah hara pada tanah (Darmosarkoro and Rahutomo, 2010). Hal ini sejalan dengan 
penelitian pemanfaatan TKKS di Kebun Begerpang, PT. PP Lonsum yang mengaplikasikan TKKS dengan dosis $200 \mathrm{~kg}$ pohon-1 ditebar antara dua pohon dalam satu baris diluar piringan, pada lahan pertanaman umur 19 tahun juga menunjukkan perbedaan kadar bahan organik yang nyata antara lahan aplikasi TKKS dan tanpa aplikasi TKKS. Rataan bahan organik tanah yang tertinggi terdapat pada kedalaman 0-10 cm pada lahan aplikasi TKKS dengan rata-rata 6,93\%, (Sakiah, Dibisono and Irawan, 2018).

Bahan organik mempunyai peranan penting sebagai bahan pemicu kesuburan tanah, baik secara langsung sebagai pamasok hara bagi organisme authotrof (tanaman) juga sebagai sumber energi bagi organisme heterotrof (fauna dan mikroorganisme tanah). Meningkatnya aktivitas biologi tanah akan mendorong terjadinya perbaikan kesuburan tanah, baik kesuburan fisik, kimia maupun biologi tanah. Perbaikan sifat fisik, kimia dan biologi tanah yang searah dengan kebutuhan tanaman (plant requirement) target akan mampu memperbaiki pertumbuhan dan produksi tanaman (Subowo, 2010).

Total Mikroba Tanah. Mikroorganisme adalah organisme yang berukuran sangat kecil sehingga tidak dapat dilihat dengan mata telanjang. Mikroorganisme dapat disebut mikroba atau jasad renik (Marianah, 2016). Perbandingan total mikroba pada lahan aplikasi dan tanpa aplikasi TKKS di Afdeling I, Kebun Adolina dapat dilihat pada Tabel 2.

Tabel 2. Hasil analisis independent sample test total mikroba tanah pada lahan aplikasi dan tanpa aplikasi TKKS kedalaman 0-20 cm dan 20-40 cm

\begin{tabular}{|c|c|c|c|c|c|c|c|c|c|c|c|}
\hline \multirow{3}{*}{$\begin{array}{l}\text { Total } \\
\text { Mikroba }\end{array}$} & \multirow{3}{*}{$\begin{array}{c}\text { Aplikasi } \\
\text { TKKS } \\
\left(\mathrm{CFU} \mathrm{ml}{ }^{-1}\right)\end{array}$} & \multirow{3}{*}{ 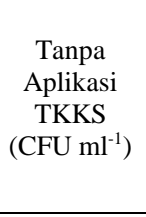 } & \multicolumn{4}{|c|}{$\begin{array}{c}\text { Levene's Test for } \\
\text { Equality of Variances }\end{array}$} & \multicolumn{5}{|c|}{ t-test for Equality of Means } \\
\hline & & & \multirow[b]{2}{*}{$\mathrm{F}$} & \multirow[b]{2}{*}{ Sig. } & \multirow[b]{2}{*}{$\mathrm{t}$} & \multirow[b]{2}{*}{ df } & \multirow[b]{2}{*}{$\begin{array}{l}\text { Sig. }(2- \\
\text { tailed) }\end{array}$} & \multirow[b]{2}{*}{$\begin{array}{c}\text { Mean } \\
\text { Difference }\end{array}$} & \multirow[b]{2}{*}{$\begin{array}{l}\text { Std. Error } \\
\text { Difference }\end{array}$} & \multicolumn{2}{|c|}{$\begin{array}{l}95 \% \text { Confidence } \\
\text { Interval of the } \\
\text { Difference }\end{array}$} \\
\hline & & & & & & & & & & Lower & Upper \\
\hline $\begin{array}{l}\text { Kedalaman } \\
0-20 \mathrm{~cm} \\
\text { Kedalaman }\end{array}$ & $24,20 \times 10^{5}$ & $3,01 \times 10^{5}$ & 4.283 & .107 & 2.541 & 4 & .064 & 211.900 & 834.087 & $\begin{array}{c}- \\
196.795 \\
-\end{array}$ & 4.434 .795 \\
\hline $20-40 \mathrm{~cm}$ & $10,37 \times 10^{5}$ & $3,46 \times 10^{5}$ & .002 & .971 & 2.258 & 4 & .087 & 749.667 & 332.064 & 172.291 & 1.671 .624 \\
\hline
\end{tabular}

Nilai t-hitung total mikroba tanah pada kedalaman 0-20 cm $(2.541)<\mathrm{t}$ - tabel $(0,05)(4)(2.776)$ artinya bahwa hipotesis H0 diterima yaitu tidak ada perbedaan total mikroba pada lahan aplikasi TKKS dan tanpa aplikasi TKKS. Secara statistik tidak menunjukkan perbedaan total mikroba pada lahan aplikasi dan tanpa aplikasi TKKS di kedalaman 0-20 cm, rata-rata total mikroba pada lahan aplikasi TKKS yaitu 24,20 x 105 CFU ml-1 sedangkan pada lahan tanpa aplikasi TKKS yaitu 3,01 x 105 CFU ml-1. Pada kedalaman 20-40 $\mathrm{cm}$, nilai t-hitung $(2.258)<\mathrm{t}$ - tabel(0,05)(4)(2.776) artinya bahwa hipotesis H0 diterima yaitu tidak ada perbedaan total mikroba pada lahan aplikasi TKKS dan tanpa aplikasi TKKS. Total mikroba pada lahan aplikasi TKKS kedalaman 20-40 cm yaitu 10,37 x 105 CFU ml-1 dan pada lahan tanpa aplikasi TKKS 3,46 x 105 CFU ml-1.

Dekomposisi TKKS menjadi bahan organik tidak terlepas dari peran organisme tanah. Sebagai perekayasa lingkungan, fauna tanah berperan langsung merombak bahan organik secara mekanik termasuk didalamnya adalah siput, cacing tanah, kaki seribu, semut dan rayap. Dalam aktivitasnya mereka menggigit dan mengunyah serasah menjadi ukuran yang lebih kecil sehingga akan mempermudah proses dekomposisi oleh mikroorganisme tanah (Widyati, 2013). Pada penelitian (Sakiah, Sembiring and Yairawati Duha, 2016) di kebun Surya Mata IE PT Mopoli Raya bahwa pada lahan aplikasi TKKS ditemukan fauna tanah dari golongan arthropoda yang dominan yaitu Myrmica rubra (semut merah), Nanotermes isaacae ( kecoak) dan Lumbricus terrestris (cacing merah). Dalam penelitian lain di kebun Begerpang PT. PP Lonsum bahwa total mikroba pada lahan aplikasi TKKS berbeda nyata dengan total mikroba pada lahan tanpa aplikasi TKKS. Total mikroba pada lahan aplikasi TKKS 17,05 x 106 CFU ml-1 dan pada lahan tanpa aplikasi TKKS 3,55 x 106 CFU ml-1 (Sakiah, Dibisono and Irawan, 2018). 
Pada penelitian ini ditemukan total mikroba pada lahan aplikasi TKKS kedalaman 0-20 cm yaitu 24,20 x 105 CFU ml-1 dan pada kedalaman 20-40 cm yaitu 10,37 x 105 CFU ml-1. Total mikroba pada lahan tanpa aplikasi TKKS kedalaman 0-20 cm yaitu 3,01 x 105 CFU ml-1 dan pada kedalaman $20-40 \mathrm{~cm}$ yaitu 3,46 x 105 CFU ml-1. Setiap spesies mikroorganisme mempunyai persyaratan tertentu untuk pertumbuhannya dan jika lingkungannya tidak sesuai, pertumbuhan atau aktivitasnya akan menurun sehingga mempengaruhi total populasinya. Secara umum, aktivitas mikroorganisme dalam suatu profil tanah sangat ditentukan oleh ketersediaan substrat energi dan unsur hara anorganik. Disamping itu pertumbuhan dan aktivitas mikroorganisme ditentukan oleh sifat fisik dan kimia tanah. Sifat fisik tanah meliputi temperatur, tekanan osmotik, tegangan permukaan, radiasi, kekentalan (viscosity), fenomena adsorpsi. Sedangkan sifat kimia tanah yang berpengaruh meliputi air, $\mathrm{pH}$, kualitas dan kuantitas hara organik dan anorganik, udara, senyawa pendorong dan penghambat pertumbuhan, oksidasi dan reduksi (Marianah, 2016).

Respirasi Tanah. Respirasi mikroba (respirasi tanah) didefinisikan sebagai penyerapan oksigen atau evolusi karbon dioksida oleh bakteri, jamur, alga dan protozoa, dan termasuk pertukaran gas dari metabolisme aerob dan anaerob (Anderson, 1982). Respirasi tanah merupkan salah satu indikator aktivitas mikroba dalam mendekomposisi bahan organik (Widati, 2012). Respirasi tanah pada lahan aplikasi dan tanpa aplikasi TKKS di Afdeling I, Kebun Adolina dapat dilihat pada Tabel 4.

Tabel 4. Hasil analisis independent sample test respirasi tanah pada lahan aplikasi dan tanpa aplikasi TKKS kedalaman 0-20 cm dan $20-40 \mathrm{~cm}$

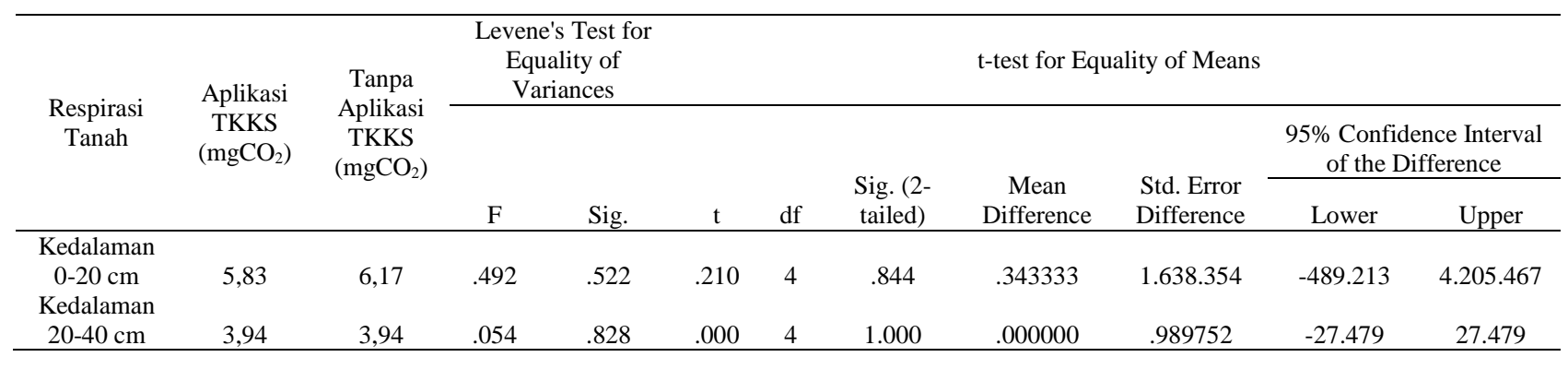

Hasil analisis menunjukkan bahwa nilai t-hitung respirasi tanah kedalaman 0-20 cm yaitu $(0.210)<\mathrm{t}$ tabel(0,05)(4)(2.776) artinya bahwa hipotesis H0 diterima yaitu tidak ada perbedaan respirasi tanah pada lahan aplikasi TKKS dan tanpa aplikasi TKKS. Rata-rata respirasi tanah pada lahan aplikasi TKKS kedalaman 0-20 cm adalah 5,83 mgCO2 dan pada lahan tanpa aplikasi TKKS 6,17 mgCO2. Pada kedalaman 20-40 cm, rata-rata respirasi tanah pada lahan aplikasi TKKS dengan tanpa aplikasi TKKS kedalaman menunjukkan rata-rata yang sama yaitu 3,94 mgCO2. Anas (1989) menyebutkan bahwa respirasi tanah dapat mencerminkan tingkat aktivitas mikroorganisme dalam tanah, yaitu jumlah produksi $\mathrm{CO} 2$ yang dihasilkan mikrooganisme berbanding lurus dengan jumlah mikrooganisme tanah, jika aktivitas mikrooganisme tinggi maka produksi CO2 juga tinggi. Namun, pada penelitian ini dapat dilihat bahwa total mikrooganisme tanah tidak berbanding lurus dengan produksi CO2 yang dihasilkan. Peningkatan respirasi dapat disebabkan oleh perubahan lingkungan yang luar biasa. Secara keseluruhan iklim akan mempengaruhi fisiologi organisme tanah, misalnya aktivitas dan pertumbuhan mereka akan meningkat ketika suhu dan kelembaban tanah meningkat (Widyati, 2013).

\section{KESIMPULAN}

Pemanfaatan TKKS dosis 35 ton ha-1 yang ditebar merata tanpa berlapis antar pokok baris tanaman kelapa sawit umur 13 tahun di kebun Adolina PT. Perkebunan Nusantara IV dapat meningkatkan kadar bahan organik tanah kedalaman $0-20 \mathrm{~cm}$. Kadar bahan organik tanah lebih tinggi pada lahan aplikasi TKKS 
dibanding pada lahan tanpa aplikasi TKKS, namun aplikasi TKKS tidak meningkatkan total mikroba dan respirasi tanah.

\section{DAFTAR PUSTAKA}

Anas, I. (1989) Biologi Tanah dalam Praktek. Bogor: Pusat Antar Universitas Bioteknologi IPB.

Anderson, J. P. E. (1982) Soil Respiration, Methods of Soil Analysis. 2nd edn. Institut fur Budenbiologie. Available at: https://dl.sciencesocieties.org/ publications/books/ abstracts/ agronomymonogra/methodsofsoilan2/831.

Anggraini, D. and Roliadi, H. (2011) 'Pembuatan Pulp dari Tandan Kosong Kelapa Sawit untuk Karton pada Skala Usaha Kecil', Jurnal Penelitian Hasil Hutan, 29(3), pp. 211-225.

Dariah, A. (2007) 'Bahan Pembenah Tanah : Prospek dan Kendala Pemanfaatannya', Tabloid Sinar Tani, pp. 1-3.

Darmosarkoro, W. and Rahutomo, S. (2010) 'Tandan Kosong Kelapa Sawit Sebagai Bahan Pembenah Tanah', in Lahan dan Pemupukan. Medan: Pusat Penelitian Kelapa Sawit, pp. $167-179$.

Dirjenbun (2016) Statistik Perkebunan Indonesia. Edited by D. D. Hendaryati et al. Jakarta: Direktorat Jenderal Perkebunan. Available at: http://ditjenbun.pertanian.go.id.

Giyanto and Sinaga, H. (2019) 'The Making and Quality Testing of Bio-Briquette from Oil Palm Waste Raw Materials as an Alternative Energy', International Journal of Energy Engineering, 2019(1), pp. 1-6. doi: 10.5923/j.ijee.20190901.01.

Gurmit, S., Manoharan and San, T. (1989) 'United Plantations' approach to palm oil mill byproduct management and utilization', in PORIM International Palm Oil Development Conference. Malaysia: Palm Oil Research Institute of Malaysia, pp. 225-234.

Marianah, L. (2016) Mikroorganisme Penting Dalam Tanah. Available at: http://www. bppjambi.info/newspopup.asp?id=696.

Putri, A. and Wardani, K. (2014) 'Pemanfaatan Tandan Kosong Kelapa Sawit Sebagai Material Tekstil Dengan Pewarna Alam Untuk Produk Kriya', Jurnal Tingkat Sarjana bidang Senirupa dan Desain, 1, pp. 1-10. Available at: https://www.neliti.com/ publications /243069/pemanfaatan-tandan-kosong-kelapa-sawit-sebagai-material-tekstil-denganpewarna-a\#cite.

Said, E. G. (1996) 'Penanganan dan Pemanfaatan Limbah Pada Kelapa Sawit', Trubus Agriwijaya.

Sakiah, Dibisono, M. Y. and Irawan, R. I. (2018) 'Analysis Of Total Microbes, Organic Materials And Soil Respiration On Application Land And Without Application Of Palm Oil Empty Bunch', Jurnal Agro Estate. Medan, 2(2), pp. 109-115. Available at: https://ejurnal.stipap.ac.id/index.php/JAE/article/view/49.

Sakiah, Sembiring, M. and Yairawati Duha, A. (2016) 'Populasi Arthropoda Pada Lahan Aplikasi dan Tanpa Aplikasi Tandan Kosong Kelapa Sawit di Afdeling Upah Kebun Surya Mata IE PT. Mopoli Raya', Jurnal Agro Estate. Medan, 7(2), pp. 132-142. 
Sembiring, M., Sipayung, R. and Sitepu, F. E. (2014) 'Pertumbuhan dan Produksi Kacang Tanah dengan Pemberian Kompos Tandan Kosong Kelapa Sawit pada Frekuensi Pembumbunan yang Berbeda', 2(2337), pp. 598-606. Available at: https://jurnal.usu.ac.id/index.php /agroekoteknologi/article/view/7066/2894.

Silalahi, B. and Supijatno, M. (2017) 'Waste management of palm oil (Elaeis guineensis Jacq.) in Angsana Estate, South Kalimantan', Bul. Agrohorti, 5(3), pp. 373-383.

Subowo (2010) 'Strategi efisiensi penggunaan bahan organik untuk kesuburan dan produktivitas tanah melalui pemberdayaan sumberdaya hayati tanah', Jurnal Sumberdaya Lahan, 4(1), pp. $13-25$.

Suriadikarta, D, A. and Simanungkalit, R. D. M. (2012) 'Pendahuluan', in Pupuk Organik dan Pupuk Hayati. Bogor: Balai Besar Litbang Sumber Daya Lahan Pertanian, pp. 1-9.

Wahyuni, M. and Sakiah (2019) Buku Ajar Jenis Pupuk dan Sifat-Sifatnya. Medan: USU Press.

Widati, S. (2012) 'Respirasi Tanah', in Metode Analisa Biologi Tanah. Bogor: Balai Besar Litbang Sumber Daya Lahan Pertanian.

Widyati, E. (2013) 'Pentingnya Keragaman Fungsional Organisme Tanah Terhadap Produktivitas Lahan', Tekno Hutan Tanaman, 6(1), pp. 29-37. Available at: http://www.fordamof.org/files/Tekno_6.1.2013-4.EnnyWidyati.pdf. 